\title{
RECENT ADVANCES RELATING TO THE COMPOSITION AND ANALYSIS OF EDIBLE OILS AND FATS.*
}

\author{
By E. RICHARDS BOLTON AND CECIL REVIS.
}

THE marked development in the oil industry during the last few years, while it has led to a concomitant development of industrial processes, has certainly not been accompanied by a parallel extension of our analytical knowledge on the purely chemical side of oils and fats. It is not too much to say that we are still very dependent on the almost rule-of-thumb methods which have prevailed in this department of analytical chemistry up to the present time; nor, unfortunately, is there much promise as yet that any more scientific methods are likely to come into use. This is a natural result of the highly complex character and overlapping constitution of the natural fatty products.

For this reason it has seemed advisable to collect the work of the last few years under a number of separate headings, rather than to attempt to show the interrelation of the work as a whole. These headings are :

(a) Constitution and Composition of Natural Glycerides.

(b) Hydrogenated Fats.

(c) Analytical Methods.

(a) Constitution and Composition of Natural Glycerides.-What little addition to our knowledge has been made in this direction has resulted chiefly from the study of the hydrolysis of known glycerides by various agents, and from attempts at the

* This is the third of a series of articles dealing with recent advances in certain branches of analytical work. Others will follow at intervals.-EDIToR. 
synthesis of such glycerides, and from the study of the melting-points of both fats and fatty acids.

The saponification of triolein by alcoholic potassium hydroxide has been investigated by Fortini (Chem. Zeit., 1912, 36, 1117). The speed of reaction during fractional saponification being studied, the results show three distinct phases in the chemical process. He deduces from his findings that these phases correspond to the successive degradation into diglyceride, monoglyceride, and fatty acid. These results, however, only confirm the earlier experiments of Geitel and Lewkowitsch. With these experiments must be contrasted the results of Grün and Correlli (Zeitsch. angew. Chem., 1912, 25, 665 ; ANaLYst, 1912, 37, 256), who have examined the hydrolysis of tripalmitin with concentrated sulphuric acid. In their experiments no trace of the formation of monoglyceride was obtained, the products of the reaction being always free fatty acid, dipalmitin and unchanged triglyceride. Similar results were obtained with tristearin.

They infer from these experiments the formation of diglyceride sulphuric acid ester, and an $a \beta$-distearin sulphuric acid ester has been prepared by them, though this could not be isolated from the reaction mixtures, which is easily explained by the great instability of the ester in the presence of water.

The synthesis of natural glycerides from the point of view of the phase rule has been investigated by Kremann, Schoulz, Klein, and Kropsch (Monatsh., 1912, 33,1063 ; 1913, 34, 1291; and 1914, 35, 561). The ternary system, (1) tristearintripalmitin-triolein, (2) tripalmitin-stearic acid-palmitic acid, and (3) tristearin-stearic acid-palmitic acid, have been studied. The work has entailed the determination of the freezing-points of a very large number of mixtures of these substances, but whilst the results obtained are largely of theoretical interest, they appear to throw a certain amount of light upon the probable composition of the hard and soft fats which are chiefly composed of the above-mentioned glycerides. An attempt at the direct synthesis of glycerides has been made by Bellucci (Gazz. Chim. Ital., 1912 42, ii., 283) by 'heating equal molecular proportions of palmitic, oleic, and stearic acids with glycerol at high temperatures and greatly reduced pressure. The formation of glycerides under these conditions proceeds along very similar lines to those followed when the synthetic agent is the lipase of castor oil seed. While these three acids vary greatly in the speed with which they are changed into glycerides, the general course of the reaction is of an exactly opposite character to that obtained by Fortini (loc. cit.) in his experiments on saponification.

Before leaving the subject of glycerides mention may be made of the suggestion of Bömer and Limprich (Zeitsch. Unters. Nahr. Genussm., 1913, 25, 354 ; A.ALust, $1913,38,214$ ), that in describing mixed glycerides the following nomenclature, which enables isomeric glycerides to be described graphically without confusion, should be employed :

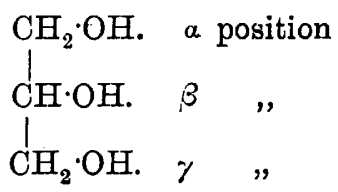


The $\alpha$ and $\gamma$ positions are of equal value when only two fatty acid radicles are present in the same molecule.

The decomposition of fats and fatty acids by the action of moulds has been made the subject of investigation by Spieckermann (Zeitsch. Unters. Nahr. Genussm., 1912, 23, 306, and 1914, 27, 83). Under the action of moulds (penicillium, aspergillus, and monilia) the glycerides are hydrolysed to glycerol and fatty acid, by means of a lipase which appears to be extracellular, the glycerol is almost completely converted into carbon dioxide and water by the mould, a certain proportion of the fatty acid being absorbed by the cells, probably in the form of a soap solution.

The fatty acids show very varying resistance to the action of the mouldsstearic and arachidic acids being but slightly attacked, while myristic and lauric acids were almost completely decomposed and absorbed. The residual fatty acids unabsorbed by the moulds show distinct evidence of change; for instance, the iodine value of oleic acid is reduced, while that of the saturated fatty acid is of ten increased. These results are of distinct interest in connection with the question of rancidity and accounts for the fact that the oils and fats of the coconut group, which have a large content of lauric acid, are peculiarly susceptible to rancidity when acted upon by moulds.

Some interesting papers have been published in connection with the meltingpoints of fats which throw some light on the anomalies observed in such determinations. That of Le Chatelier and Mlle. Cavaignac (Compt. rend., 1913, 156, 589), working with a coconut oil product and with "stearine," shows that the change of state at the melting-point does not really differ from that of chemical compounds in general, and is a strictly reversible phenomenon, but often takes place exceedingly slowly. The variation between the melting-point and solidifying-point of fats, as commonly determined in analytical work, is, therefore, solely the result of the comparatively rapid way in which such determinations are made. The solidification temperature, as a rule, shows much greater departure from the true value than does the melting-point.

Grün (Berichte, 1912, 45, 3691) has brought forward more evidence in support of the theory that glycerides exist in two modifications, and deduces from his results the reasons for the variability in the melting-point of fats prepared by different processes, and bas also prepared some of these modifications which appear to uphold his contentions. The general results of his investigations are to be taken as supporting the view that the final condition of a glyceride is the result of an equilibrium between those modifications which, in some cases, may only be attained slowly. Somewhat similar results have been obtained by Smits and Bokhurst (Proc. K. Akad. Wetensch., Amsterdam, 1912, 15, 681), who have shown the existence of two such crystalline modifications when working with tristearin.

Arising out of the above results there appears ground for the opinion of Twitchell (J. Ind. and Eng. Chem., 1914, 6, 564; ANaLrst, 1914, 39, 448) that the lowering of the solidifying-point in mixtures of fatty acids is of no value as an indication of their composition, while the lowering of the melting-point is.

According to Bonzio and Gastaldi (Gazz. Chim. Ital., 1912, 42, ii. 92), the position of the double links of the oleic acid series can be ascertained by a determination of 
the iodine value, as when this linkage is distant from the carboxyl groups the value obtained agrees with that required by theory, while if it be in the $2: 3$ position the results are too low, evidently due to intramolecular action taking place during the process.

Attention may be drawn to a method originated by Arnold (Zeitsch. Unters. Nahr. Genussm., 1912, 23, 129 ; ANaLyst, 1912, 37, 203) for the determination of the molecular weight of small quantities of fatty acids by saponification with alcoholic potassium hydroxide. The formulæ given by him appears to give very satisfactory results.

(b) Hydrogenated Fats.-It is not too much to say that the process known generally as the hydrogenation or "hardening" of fats has made almost a revolution in the history of fats and oils. Not only has this effected the production of new fatty substances hitherto quite unknown and almost unthought of, but has also brought before the analyst an entirely new series of problems of a most difficult character. The old analytical landmarks have in many cases disappeared, and the amount of sure ground at his disposal is by no means large. Though the process of introducing hydrogen into unsaturated oils and fats may be said to start from the year 1896, it was only in 1903 that the first effective patents became commercially used, and the full development of such processes is in the distant future. Since 1903 an enormous number of patents and modifications of the original process have been published, and it is quite impossible within the scope of such an article as this to do anything but touch lightly upon the work of the last few years. The developments which had taken place up to the year 1913 have been fully dealt with by Ellis in a paper read before the New York section of the Society of Chemical Industry (J. Soc. Chem. Ind., 1912, 31, 1155). The chief developments from a commercial point of view have centred round the finding of the most suitable catalyst for the production of the change and the temperature at which the process can be most economically worked. Among catalysts which have been proposed are platinum, palladium, nickel oxide, nickel carbonyl, cobalt, copper, iron, and a mixture of some of these ; and, quite recently, Bergius (Zeitsch. angew. Chem., 1914, 27, 522) claims that the change can be brought about without any catalyst at all under a high pressure of hydrogen at high temperatures. At this present moment, however, nickel appears to be the favourite catalyst, though the method by which it is employed varies considerably, and is the chief subject of the greater number of patents which have been taken out. The catalyst is usually made by the preparation of its oxide from a nickel salt and the reduction of the latter in hydrogen, the object being to obtain the nickel in a very finely divided state. The question of the details and cost of the catalytic hydrogenation of fats is dealt with in a paper by Bontoux (Les Matières Grasses, 1914, 7, 4194). The process has also enabled such oils as whale oil to be used, and the product is becoming known commercially as " artificial tallow," a large factory having been erected at Fredrickstad (Board of Trade Journal, 1913, May 29; see also Chem. Zeit., 1914, 38, 392). It also appears that (Thompson, Amer. Perfumer, 1914, 9, 139) in the United States, compound lards are now almost entirely hydrogenated cotton-seed oil.

The questions of the digestibility of the hydrogenated fats, and of the possible 


\section{BOLTON AND REVIS: RECENT ADVANCES RELATING TO THE}

danger to health from traces of the catalyst, have not yet been satisfactorily settled, and it is not improbable that any decision adverse to their production would meet with considerable opposition both on account of their extreme utility and of their value as substitutes for animal fats.

Some experiments have been carried out by Lehmann (Chem. Zeit., 1914, 38, 798), who finds that commercially hardened oils contain from 0.07 to 6 mgrms. of nickel per kilo, and has carried out a number of feeding experiments both on animals and on human beings, which appear to show that no ill effects result from the consumption of these fats. Offerdahl-Larvik (Ber. deutch. Pharm. Ges., 1913, 23,558 ) goes so far as to state $0.5 \mathrm{grm}$. of nickel per day is not harmful.

The question has, however, lost a little of its interest, as the removal of the catalyst is ever so much more perfect at present than it was originally, which, while satisfactory from the point of view of the consumer, cannot be regarded in the same light by the analyst. The nickel is undoubtedly held by the fats in the form of nickel soaps.

The chemical changes accompanying hydrogenation have been little investigated. As would be expected, the iodine value diminishes, while the melting-point and the solidifying-point rise, and, as the process may be stopped at any stage, a whole series of products may be obtained from the same original fat, varying, in the case of such an oil as cotton-seed, from substances but little different outwardly to the original oil, up to a hard product almost resembling marble.

According to Norman and Hugel (Chem. Zeit., 1913, 37, 815 ; ANalyst, 1913, 38, 432), hydroxyl groups are split off during the hardening process, and acids such as arachidic and behenic acids are formed during the treatment of marine animal oils.

Though theoretically the process consists of the introduction of hydrogen atoms into the unsaturated linkages of the glyceride, it is highly improbable that the process is actually so simple, and Leimdorfer (Seifensieder Zeit., 1913, 40, 1317) is of the opinion that the "stearine" of the hydrogenated fat is different to natural "stearine," and is probably an allotropic modification, the speed of saponification being greater than in the case of the natural fat. It is evident, to anyone working with these fats, that their general character and microscopical appearance differ markedly from that of natural fats. With the above-mentioned molecular changes which take place on hydrogenation, there also occurs the disappearance of those substances which are the cause of reactions so characteristic of certain natural fats. Bömer (Zeitsch. Unters. Nahr. Genussm., 1912, 24, 104 ; ANALyst, 1912, 37,452 ) states that the Halphen, Baudouin, and other colour reactions are rendered negative by hydrogenation, and this is undoubtedly so in the case of Halphen's reaction; the chromogenetic substance appears to be almost entirely destroyed before any appreciable quantity of "stearine" is formed. Kreis and Roth (ibid., 1913, 25, 81 ; ANALYST, 1913, 38, 160), however, state that the nitric acid-resorcinol test is not nullified, and holds good for the oil after treatment. According to Stiepel (Siefensieder Zeit., 1912, 39, 953), the octobromide test, which is so useful in examination for marine animal oils, is rendered practically useless by the process of hydrogenation. The only test which is available with the same certainty after treatment as before is the phytosteryl-acetate test, which has accordingly assumed 
even more importance than it has hitherto done, and on which account great interest attaches to the digitonin methods of performing the test, reference to which is made in Section (c) on Analytical Methods.

(c) Analytical Methods.-The past few years have not been prolific of methods of great interest in connection with the analysis of oils and fats, the published work having been directed rather towards the improvement and refinement of existing methods.

In connection with the specific gravity of oils, Ransome (J. Soc. Chem. Ind., 1912, 31, 672 ; ANalyst, 1912, 37, 410) has drawn attention to the fact that this figure may be considerably altered by the presence of free fatty acids, particularly in connection with olive oil.

A comparative study of the Hïbl and Wijs method for the determination of the iodine value of oils and fats has been made by Auguet (Ann. Falsif., 1912, 5, 459), who confirms the superiority of the Wijs method, and at the same time elucidates some of the causes of the discrepancies between the two methods. In spite of the debt which we owe to the Hübl method for the early recorded iodine values, it would be of advantage if the Wiis method were the only recognised one for carrying out this test.

The Bellier test for the detection and estimation of arachis oil has been the subject of critical study by Evers (ANALYst, 1912, 37, 487), who, following on the lines of Adler (Zeitsch. Unters. Nahr. Genussm., 1912, 23, 676) and of Franz (Dis. München., 1910), has succeeded in clearly pointing out the weak points of the original method, and has evolved a practical and satisfactory procedure for conducting this well-known and useful method. The error seems to have chiefly arisen through a mistaken idea that the precipitates of arachidic and lignoceric acids were insoluble in 70 per cent. alcohol. Later, however, Lüers (Zeitsch. Unters. Nahr. Genussm., 1912, 24, 683), using the method of Franz and Adler (loc. cit.), has shown that in certain samples of olive oil, containing abnormally high proportions of myristin, a misleading result, pointing to the presence of arachis oil, may be obtained, but that an increase in the quantity of acetic acid will obviate the difficulty. Kreis and Roth (Zeitsch. Unters. Nahr. Genussm., 1913, 25, 81), however, sound a note of warning, which is very necessary at this time, with regard to the impossibility of applying Bellier's test to "hardened oils," and have themselves proposed a method whereby the difficulty may be overcome.

A great number of papers have been published in connection with Tung oils, the growing demand for which has necessitated a greater care in the examination of the commercial product. Most of these centre round the "heat polymerisation test," and many so-called standard methods have been put forward, chiefly from American sources; see Browne (Chem. News, 1912, 106, 14 ; Analyst, 1912, 37, 410), and the recommendation of the New York Produce Exchange (J. Soc. Chem. Ind., 1912, 31, 997) and Potsdamer (ibid., 1913, 32, 542).* The nature of the body formed during this test has been investigated by Wolff (Chem. Zeit., 1913, 37, 1376), who shows that the jelly is not a homogeneous substance, but that the setting is due to the solution of

* See also specification for South China wood oil, issued by the Association of Exporters and Dealers of Hong-Kong, in which details for carrying out some of the tests are given. 


\section{BOLTON AND REVIS : RECENT ADVANCES RELATING TO THE}

the altered portion of the oil in the unaltered part followed by the final gelatinisation of the solution. The chemical transformations which take place have also been investigated by Folkin (J. Russ. Phys. Chem. Soc., 1913, 45, 283), and in this connection attention may be drawn to an interesting paper by Morrell (J. Chem. Soc., 1912, 101,2082 ) on the behaviour of elaeo-stearic acid.

The analysis of both Chinese and Japanese wood oils has been made the subject of a very careful investigation by Chapman (ANALYsT, 1912, 37, 543), who has succeeded in placing the matter in a much more satisfactory condition. Some further work has been published by Ware and Schumann (J. Soc. Chem. Ind., 1914, 33, 1017 ; Analyst, 1914, 39, 557).

Gastaldi (Chem. Zeit., 1912, 2, 758) has published an investigation into the actual cause of the Halphen colour reaction for cotton-seed oil, and concludes that impurities in the amyl alcohol employed are responsible. He shows that a great variety of substances could be used instead of amyl alcohol, and particulary recommends the use of pyridine, which undoubtedly greatly improves the sensitiveness of the test, particularly if carried out in closed tubes. He goes so far as to state that 0.25 per cent. of cotton-seed oil can be detected. Utz (Chem. Rev. Fiett-Ind., $1913,20,291$ ), proposing to use pentachlorethane instead of carbon disulphide as the sulphur solvent, has been attacked by the former author, who states that his test is still further improved by a reduction in the quantity of carbon disulphide, the liquid being heated to $140^{\circ} \mathrm{C}$. These refinements of the original Halphen test are not without value, as the increasing use of "hardened" cotton-seed oil calls for this greater delicacy, the chromogenetic substance being largely destroyed in the process of hydrogenation. The excessive quantity of carbon disulphide generally employed will be appreciated when one considers a test proposed by Milliau (ANALYST, 1912, 37, 101), who has ingeniously taken advantage of the delicate Halphen reaction with kapok oil, conversely to detect minute traces of carbon disulphide in commercially "extracted" oils. This test is carried out by distilling 50 grms. of the oil with 10 c.c. of pure amyl alcohol; 1 c.c. of kapok oil is added to the first 4 c.c. of the distillate, which, together with a few mgrms. of sulphur, are heated in a sealed tube for one hour in a water-bath. The writers have found it possible to detect as little as 0.02 per cent. of carbon disulphide by this means, and when the amounts are small have even made approximate estimates of the quantity by comparison with standards prepared from oils containing known quantities of carbon disulphide. Norman (ANALYst, 1912, 37, 508) has put forward a rapid method for obtaining acetyl values, whereby he claims to obviate errors caused by esterification of acetylated fatty acids when dissolved in alcohol. Simmons (ANaLYst, 1915, 491) has carried out some useful work on the formylation of essential oils and their alcoholic constituents, and he compares the figures obtained with those yielded by acetylation. A consideration of his figures and data open out a new field of investigation in the examination of fatty oils, the method being likely to give information similar to the acetyl value in a more expeditious manner. A simple method is given by Arnold (ANALYst, 1912, 37, 203) for the determination of the molecular weight of small quantities of fatty acids by titration with potassium hydroxide, and weighing the soap after a special method of 
drying. The author claims to obtain molecular weights within two units of theory. Bolton, Richmond, and Revis (Analyst, 1912, 37, 183), have applied the ReichertMeissl, Polenske, and Kirschner tests to a series of mixtures of coconut and palm kernel oils with butter fat, in the presence of other fats and oils. The figures they have obtained show that the quantity of butter fat in margarine can be estimated within about 1 per cent. in the presence of either coconut or palm kernel oil, or both together.

They express the opinion that the relationship between the Polenske and Kirschner values is both more constant and more sensitive than the relationship between the Polenske and Reichert-Meissl values as first put forward by Polenske.

A table was tentatively constructed by them, in the hope that it would be critically examined by other workers, which, in fact, has just been done by Cranfield (ANALYst, 1915, 439), as the result of an extensive investigation. This author, in the course of a series of feeding experiments, obtained butters which gave Reichert-Meissl, Polenske, and Kirschner values covering an extensive range from nearly the lowest to almost the highest figures commonly found. The average results agree well with the relationship proposed by Bolton, Richmond, and Revis (loc. cit.), and the author puts forward the relationship $\frac{\mathrm{RM}-\mathrm{K}}{\mathrm{P}}$ as a constant, varying between 1.97 and 2.98 , but generally between $2 \cdot 2$ and 2.8 . This he hopes to further investigate, but, as the matter stands at present, the death-knell of profitable adulteration of butter by means of either coconut or palm kernel oil, has been sounded.

The great similarity in constitution between coconut and palm kernel oil has rendered it an almost impossible task to estimate the proportion of these fats in mixtures, more especially in the presence of other fats. Burnett and Revis (ANALYST, 1913, 38, 255) have devised a method by which they believe some help is given in the solution of this problem, the process being quite independent of the presence of other fats. It consists of a determination of the "turbidity temperature" of an alcoholic solution (of certain strength) of the barium salts of the insoluble volatile acids, as obtained when determining the Polenske value.

Some very useful work on Egyptian butter, samna, and ghee, is recorded in a paper by Trimen (ANALYst, 1913, 38, 243), who gives constants for a large number of samples of these products. He applied many of the lately proposed methods, and adds his conclusions and criticisms of their value. His figures for the ReichertMeissl value of pure ghee confirm those of certain other observers, and tend to prove that the low figure unfortunately put forward by Kesava-Menon ( $J$. Soc. Chem. Ind., 1910, 29, 1428), for one sample only, must be regarded as strangely abnormal. The author has applied the Ave Lallement method to some forty samples, and obtained in every case minus values for $b-(200+c)$, thus showing that Lallement's statement applies to butter made from the milk of the buffalo and the sheep, as well as to that made from cow's milk; but he points out that, in cases where large minus values were obtained, he was able to add large quantities of coconut oil and produce a mixture which still gave a minus value. He concludes from this that the writers' commendation of the Avé Lallement process (Allen's 
"Commercial Organic Analysis," fourth edition, vol. ii., 288) is not justified. This is a little unfortunate, as such commendation was never directed towards this useful process as a means of detecting coconut oil, since the presence of 5 per cent. of this oil is readily disclosed by the relationship of the Polenske and Kirschner values, but rather to its value for the detection of other animal fats in butter-a problem of much greater difficulty.

The existence of an official method for estimating glycerol in fats has, like all standard methods, the unfortunate effect of leading every analyst into the same groove, and sadly hampering analytical enterprise in the direction of improved methods. The method of Zeisel and Fanto of converting the glycerol into isopropyliodide has been shown by Lewkowitsch (ANALYST, 1903, 28, 108) to give low results. Willstätter and Madinaveitia (ANALYsT, 1912, 37, 571) claim to have improved this method, though the figures they cite are still somewhat below that required by theory. A very simple method has been described by Bertram (ANaLYst, 1913, 38, 275), who treats the glycerol solution with excess of $\frac{\mathrm{N}}{2} \mathrm{KOH}$, adding a 10 per cent. solution of copper sulphate till a permanent precipitate is formed. An excess of potassium iodide solution is added after acidification with acetic acid, and the liberated iodine titrated with $\frac{N}{10}$ sodium thiosulphate solution, each molecule of sodium thiosulphate corresponding to two molecules of glycerol. Langheld and Zeileis (ANALYST, 1913, 38, 273) have proposed a method for the analysis of mixtures of certain lower fatty acids by fractional moist combustion with chromic acid, and measurement of the $\mathrm{CO}_{2}$ evolved at certain temperatures. Formulæ are given for calculating the proportion of acetic, isobutyric, isovaleric, and methyl-ethyl-acetic acids.

Bömer (ANaLyst, 1913, 38, 204) has isolated the saturated glycerides from lard by repeated fractional precipitation and crystallisation from ether, and finds that tristearin is absent, thereby showing a striking difference from mutton and beef fats. This observer contradicts the statement of Kreis and Hafner (ANaLyst, 1914, 29, 259) that heptadecyldistearin is present, and he identifies the insoluble glyceride as palmitodistearin, and from this suggests that it is a-palmitodistearin, that obtained from mutton fat being $\beta$-palmitodistearin. Bömer has made use of his experimental results to detect the presence of beef fat in lard and for the solution of similar problems.

A method for the detection of adulteration of linseed oil has been worked out by Elsdon and Hawley (ANaLYst, 1913, 38, 3), whereby the oil is "dried" on paper under standard conditions, and the paper extracted by ether in a Soxhlet apparatus. The test is simple and novel, and appears to give indication of crude adulteration, but the information is, after all, no more than could be obtained by a consideration of the ordinary analytical "constants."

The insoluble bromide value (sometimes known as the hexabromide test), originally worked out by Hehner and Mitchell (ANALYst, 1898, 23, 313), has since then been the subject of many researches. Of recent years, under this Society's Analytical Investigation Scheme, most valuable work has been carried out by Gemmel (ANAIYYST, 1914, 39, 297), who has exhaustively examined the sources of error in various methods of carrying out the process. Similar investigations, though on a less exten- 
sive scale, were carried out by Sutcliffe (ANALyst, 1914, 39, 28). Gemmel (loc. cit.) criticises Sutcliffe's conclusions, and the latter replied to the criticism (ANalyst, 1914, 39, 388). In view of the useful work which these observers have recorded, their points of variance are of minor importance.

Halphen's qualitative modification of this test often affords most useful information in cases of unknown oils, and helps in the detection of rape oil ; but in this connection it should be borne in mind that, as pointed out by the writers ("Fatty Foods," 43), beef fat, lard, butter fat, and shea butter give precipitates.

As already mentioned in section $(b)$ the phytosteryl acetate test has assumed much greater importance on account of the possible use of hardened vegetable fats as adulterants of animal fats. This method, always somewhat tedious, has been decidedly simplified by the employment of digitonin, first proposed in its application to fats by Marcusson and Schilling (Chem. Zeit., 1913, 37, 1001 ; ANaLyst, 1913, 38, 458). The pitfalls of this simple application of the test have been well pointed out by Klostermann (Zeitsch. Unters. Nahr. Genussm., 1913, 26, 443 ; ANaLyst, 1914, 39, 32), who has elaborated the process in such a manner that the free phytosterol and phytosteryl esters may be separately estimated. 